\title{
Effect of Co2+ Doped Seed Layer on Morphology and Photoelectric Properties of ZnO Nanoarray
}

lihua Li ( $D$ lilihua7818@163.com )

Henan University of Science and Technology https://orcid.org/0000-0003-4946-6058

\section{Qingkui Shi}

Henan University of Science and Technology

\section{Bingyang Hou}

Henan University of Science and Technology

\section{Xiangmei Ning}

Henan University of Science and Technology

\section{Qian Li}

Henan University of Science and Technology

\section{Bok-Hee Kim}

Chonbuk National University

\section{Jinliang Huang}

Henan University of Science and Technology

\section{Research Article}

Keywords: Co2+ doping, ZnO nanoarray, optical, UV-vis absorption, photoelectric properties

Posted Date: March 3rd, 2021

DOI: https://doi.org/10.21203/rs.3.rs-258768/v1

License: (c) (i) This work is licensed under a Creative Commons Attribution 4.0 International License.

Read Full License 


\title{
Effect of $\mathrm{Co}^{2+}$ doped seed layer on morphology and photoelectric properties of $\mathrm{ZnO}$ nanoarray
}

\author{
Lihua Li ${ }^{\text {a,b }}$, Qingkui Shi a,b, Bingyang Hou ${ }^{\text {a,b }}{ }^{\text {, Xiangmei Ning }}{ }^{\text {a,b }}$, Qian \\ Li $^{\text {a,b }}$, Kim BoK-Hee a,c, Huang Jinliang a,b, *
}

a School of Materials Science and Engineering, Henan University of Science and Technology, Luoyang 471023, PR China

$\mathrm{b}$ The Key Laboratory of Henan Province on Nonferrous Metallic Materials Science and Fabrication Technology, Collaborative Innovation Center of Nonferrous Metals of Henan Province, Luoyang 471023, PR China

c Division of Advanced Materials Engineering, Hydrogen and Fuel Cell Research Center, Chonbuk National University, Jeonbuk, South Korea

* Corresponding authors

* E-mail: huangj1@haust.edu.cn

\begin{abstract}
:
$\mathrm{ZnO}$ nanoarray were synthesized by hydrothermal method on $\mathrm{Co}^{2+}$-doped $\mathrm{Zn}_{1-\mathrm{x}} \mathrm{Co}_{\mathrm{x}} \mathrm{O}(\mathrm{x}(\mathrm{mol} \%)=0.00,0.01,0.02,0.03,0.04,0.05)$ seed layers pre-coated on ITO substrate. The effects of different $\mathrm{Co}^{2+}$ doping concentrations on morphology and photoelectric properties of $\mathrm{ZnO}$ nanoarray including transient photo-current and charge transfer resistance were investigated. The addition of $\mathrm{Co}^{2+}$ in the seed layer could perfect the oriented growth of $\mathrm{ZnO}$ nanoarray and apparently enhance its photo current. FESEM observation confirmed that the $\mathrm{ZnO}$ nanoarray were grown in the way perpendicular to ITO substrate along the direction of (002). Meanwhile, UV-vis tests shown that the band gap energy was decreased from $3.37 \mathrm{eV}$ to $3.16 \mathrm{eV}$ due to $\mathrm{Co}^{2+}$ doping and the $\mathrm{ZnO}$ nanoarray had a strong visible region in the range 400-650 $\mathrm{nm}$. The transient photo-current was found to vary from 0.005 to $0.15 \mathrm{~mA} / \mathrm{cm}^{2}$ under AM 1.5G simulated sunlight illumination. Photoelectric properties was correlated with the recombination of photo-generated charge carriers, which was
\end{abstract}


inhibited with optimal $\mathrm{Co}^{2+}$ doping concentrations and was beneficial for application in perovskite solar cells.

Keywords: $\mathrm{Co}^{2+}$ doping, $\mathrm{ZnO}$ nanoarray, optical, UV-vis absorption, photoelectric properties.

\section{Introduction}

One-dimensional nanomaterials have caused significant interest due to their superior properties [1]. One-dimensional $\mathrm{ZnO}$ based nanomaterials have been widely used in solar cells and other semiconductor connected fileds because it has high electron mobility, chemical stability and transition rate [2-6]. In practice application, defects/vacancies and well oriented nanoarrays of $\mathrm{ZnO}$ is crucial with reference to its related visible luminous, photocatalytic or photoelectric properties [7-10]. The modification in morphology, optical and electrical properties of $\mathrm{ZnO}$ could be realized by doping $\mathrm{ZnO}$ with metal ions (such as $\mathrm{Eu}, \mathrm{Yb}$ [11], Ag, $\mathrm{Au}$ [12], Co [13] and $\mathrm{Al}$ [14] ). Meanwhile, due to the similar ionic size of $\mathrm{Co}^{2+}(74.5 \mathrm{pm})$ and $\mathrm{Zn}^{2+}(74 \mathrm{pm})$, the $\mathrm{Co}^{2+}$ ions either substitute the cation or occupy the interstitial site in the host lattice and form Co-ZnO solid solution. Liu et al. [15] reported the well-aligned one-dimensional $\mathrm{ZnO}$ nanoarrays grown on the zinc substrates, which can confine a considerable amount of oxygen vacancies and effect the photocatalytic property with defect-related emission properties of nanoarrays. Yun et al. [16] found that the optimum length of $\mathrm{ZnO}$ nanorod based perovskite solar cells yielded a power conversion efficiency of $14.22 \%$. Wen et al. [17] also concluded that the addition of Co on a series of $\mathrm{Zn}_{1-\mathrm{x}} \mathrm{Co}_{\mathrm{x}} \mathrm{O}(\mathrm{x}=0.05,0.1,0.2,0.3)$ films could not only improve the quality of green and blue emission of the films, but also have the higher transmittance up to $90 \%$. Khan et al. [18] analyzed Co effects on the photocatalytic activity of Co-doped $\mathrm{ZnO}$ particles by chemical co-precipitation method and proved that Co doping could significantly improve the photocatalytic degradation efficiency. Kumbhar et al. [19] found that $\mathrm{Co}^{2+}$-doping could inhibit the recombination of photo-generated charge carriers. Ahmad et al. [20] demonstrated that the power conversion efficiency of the inverted organic solar cells based on the 
$\mathrm{ZnO} /$ polyaspartic acid electron transporting layers is boosted up to $16.6 \%$. Qiu et al. [21] analyzed Co effects on the photocatalytic activity of $\mathrm{Co}^{2+}$-doped $\mathrm{ZnO}$ nanorods by wet chemical method and proved that $\mathrm{Co}^{2+}$ doping could significantly improve the photocatalytic activity in the visible light. Sini et al. [22] studied the surface area and charge separation efficiency of $\mathrm{Co}^{2+}$-doped $\mathrm{ZnO}$ nanowires and nanorods, which could inhibit the recombination of photo-generated charge carriers. Khalid et al. [23] used nitrogen-doped $\mathrm{ZnO}$ nanosheets as novel electron transporting layers for highly efficient and hysteresis-free hybrid-perovskite solar cells and the maximum power conversion efficiency were $15.91 \%$. Although it has been proved that $\mathrm{ZnO}$ as catalyst has made great progress and many theory of growth mechanism are put forward to understand the growth process of $\mathrm{ZnO}$ nanoarray. However, to the best of our knowledge, a few attempts have been made about the effect of seed layer on the growth behavior and photoelectric property of $\mathrm{Co}^{2+}$ doped $\mathrm{ZnO}$ nanoarray as electron transport layer in perovskite solar cells.

In this paper, $\mathrm{Co}^{2+}$ doped $\mathrm{ZnO}$ seed layer were successfully synthesized by sol-gel method and spinned to the conductive glass substrates. The oriented growth mechanism of hydrothermally synthesized $\mathrm{ZnO}$ nanoarray on different amount of $\mathrm{Co}^{2+}$ doped $\mathrm{ZnO}$ seed layer were analyzed. The photoelectric transportation mechanism under the action of $\mathrm{Co}^{2+}$ were analyzed, which provide a foundantion for its application in perovskite solar cells.

\section{Experimental details}

\subsection{Starting materials}

$\mathrm{Co}^{2+}$-doped $\mathrm{ZnO}$ seed layers were prepared by sol-gel method using starting materials of $\mathrm{Zn}\left(\mathrm{NO}_{3}\right)_{2} \cdot 6 \mathrm{H}_{2} \mathrm{O}, \mathrm{HOCH}_{2} \mathrm{CH}_{2} \mathrm{NH}_{2}$ and $\mathrm{Co}\left(\mathrm{NO}_{3}\right)_{2} \cdot 6 \mathrm{H}_{2} \mathrm{O}$ as zinc source, stabilizer and dopant ,respectively. Subsequently, the $\mathrm{ZnO}$ nanoarray were synthesized by hydrothermal method based on the seed layers with $\mathrm{Zn}\left(\mathrm{NO}_{3}\right)_{2} \cdot 6 \mathrm{H}_{2} \mathrm{O}$ and $\mathrm{C}_{6} \mathrm{H}_{12} \mathrm{~N}_{4}$ as growth solution. All the above chemicals were analytical pure and were used as received without any further purification. 


\subsection{Preparation process of $\mathrm{Co}^{2+}$-doped $\mathrm{ZnO}$ seed layer and $\mathrm{ZnO}$ nanoarray}

ITO substrate was cleaned with detergent, acetone, anhydrous ethanol and distilled water for $10 \mathrm{~min}$, respectively. In the preparation process, a calculated amount of $\mathrm{Zn}\left(\mathrm{NO}_{3}\right)_{2}$ was dissolved in $25 \mathrm{~mL} \mathrm{CH} \mathrm{CCH}_{2} \mathrm{CH}_{2} \mathrm{O}$ to attain molarity of $0.25 \mathrm{~mol} / \mathrm{L}$. $\mathrm{HOCH}_{2} \mathrm{CH}_{2} \mathrm{NH}_{2}$ in 1:1 molar ratio and the corresponding proportion $(0-5$ mol\%) of $\mathrm{Co} / \mathrm{Zn}$-ions molar ratio was added in the above solution. The mixture was stirred at $60{ }^{\circ} \mathrm{C}$ for $2 \mathrm{~h}$, cooled down and left undisturbed for $2 \mathrm{~h}$ in the high-purity argon-filled glove box. The pink precipitate was coated three times on ITO substrate with two steps of $500 \mathrm{rpm}$ for $15 \mathrm{~s}$ and then $2000 \mathrm{rpm}$ for $30 \mathrm{~s}$ (The process is same with earlier report [24], which also adequately confirms metal ions doping in $\mathrm{ZnO}$ lattice). The samples were vacuum-dried for $10 \mathrm{~min}$ after each spin coating. The seed layer was prepared by heating the coated sample in vacuum muffle furnace at $450^{\circ} \mathrm{C}$ for $30 \mathrm{~min}$.

The $\mathrm{ZnO}$ nanoarray was synthesized by hydrothermal method on the $\mathrm{Co}^{2+}$-doped $\mathrm{ZnO}$ seed layer coated on ITO substrate with aqueous solution of $\mathrm{Zn}\left(\mathrm{NO}_{3}\right)_{2} \cdot 6 \mathrm{H}_{2} \mathrm{O}$ and $\mathrm{C}_{6} \mathrm{H}_{12} \mathrm{~N}_{4}$ at $95{ }^{\circ} \mathrm{C}$ for $7 \mathrm{~h}$ in a sealed Teflon-lined autoclave and cooled to room temperature.

\subsection{Characterization}

The crystal phase of the samples was identified by X-ray diffraction (XRD) at room temperature using $\mathrm{Cu} \mathrm{Ka}$ radiation $(\lambda=0.154 \mathrm{~nm})$ and scanning angle $(2 \theta)$ at 25 80 . The morphology of the $\mathrm{Co}^{2+}$-doped seed layers and $\mathrm{ZnO}$ nanoarray were investigated by field emission scanning electron microscopy (FESEM) with high accelerating voltage $(15 \mathrm{kV})$ and transmission electron microscopy (TEM). The optical properties were measured by UV-vis spectrometer at the range of 350-650 nm at room temperature. The photoelectric properties were measured with a three electrodes system of CHI660E equipment under simulated sunlight illumination (AM $1.5 \mathrm{G})$

\section{Results and discussions}

Fig. 1 shows XRD patterns of the samples with different Co amount of 0-5 mol\% 
on a $\log$ scale. The diffraction peaks at $31.9^{\circ}, 34.5^{\circ}, 36.4^{\circ}, 47.6^{\circ}$ and $62.9^{\circ}$ attributed to the (100), (002), (101), (102) and (103) planes are indexed according to JCPDS card No 36-1451 besides the peaks belong to ITO substrate, which corresponds to the systematic incorporation of Co-ions at $\mathrm{Zn}$-site in $\mathrm{ZnO}$ lattice. No extra peaks related to any impurity or cobalt oxide are observed within the detection limit of the instrument. The obviously enhanced intensity of (002) plane provided the evidence of emergence of single-phase hexagonal wurtzite structure with preferential orientation along the (002) crystal plane, revealed that nanoarray were grown along the c-axis. The strong sharp peaks in XRD patterns with doping show high crystallinity compared to the pure nanoarray. The intensity of (002) plane decreases with too low $(0-1 \%)$ or high doping concentrations $(5 \%)$ compared to the samples doped with $2 \%$ Co, as shown in Fig. 1, which show that the doping concentration affects the preferential orientation along the c-axis of the $\mathrm{ZnO}$ nanoarray. Co doping in the growth process of $\mathrm{ZnO}$, which can change the diffusion rate of $\mathrm{Zn}$ and $\mathrm{O}$ in the process of stacking and the surface energy of (002) plane, promoting the growth of the surface orientation. Meanwhile, the peak position shift slightly to the low angle as increasing the doping concentrations [25].

The morphological characteristics and sizes of the obtained Co-doped $\mathrm{ZnO}$ nanoarray deposited on ITO substrate under different preparation conditions are further characterized by FESEM. The morphology of the seed layer and nanoarray synthesized via hydrothermal method is shown in Fig. 2. It reveals that the $\mathrm{ZnO}$ seed layer with $2 \mathrm{~mol} \% \mathrm{Co}^{2+}$-doping are of high purity with approximate particle size of 100-150 nm (Fig. 2(a)). The ITO substrate surface is entirely covered with spherical particles, which play an important role on the subsequent growing process of $\mathrm{ZnO}$ nanoarrays. The FESEM micrographs of $\mathrm{ZnO}$ nanoarray based on above seed layer with $60 \mathrm{~nm}$ in diameter and $300 \mathrm{~nm}$ in length were presented in Fig. 2(b). The nanoarray are perpendicular to the ITO substrate surface and have enough gaps among themselves, which is very crucial for the better perovskite infiltration into the nanoarray in perovskite solar cells. The vertically grown $\mathrm{ZnO}$ nanoarrays on $\mathrm{Co}^{2+}$-doped $\mathrm{ZnO}$ seed layer with $3 \mathrm{~mol} \%, 4 \mathrm{~mol} \%$ Co have the sizes of $500-700 \mathrm{~nm}$ in 
length and $50 \mathrm{~nm}$ in diameter ,as shown in Fig. 2(c, d). The direction of all nanoarrays is slant and is not beneficial for providing a direct channel to transfer electron. It is suggested that the growing process could be the forming process of spontaneous nucleation of seed layer and directional growth of $\mathrm{ZnO}$ nanoarray. In fact, the alterations in Al-doped $\mathrm{ZnO}$ morphology are basically dependent on the growth conditions, for example reaction temperature [26] and Co doping molar ratio [27]. Hexagonal nanoarray are grown at low Co doping molar ratio of $2 \%$. Under the reaction conditions (high doping molar ratio of $3 \%$ and $4 \%$ ), the slant nanoarrys are observed. Based on the above findings, Co-doped $\mathrm{ZnO}$ nanostructures, from slant nanoarrays to perpendicularly oriented hexagonal nanoarray, are first obtained by adjusting the doping molar ratio. Thus, it can be realized that doping concentrations in the seed layer play a crucial role on the morphology alteration of $\mathrm{ZnO}$ nanoarray.

To obtain more information about the structure of $\mathrm{ZnO}$ nanoarray grown on $\mathrm{Co}^{2+}$-doped $\mathrm{ZnO}$ seed layer, the TEM images for single $\mathrm{ZnO}$ nanoarray doped with 2\% Co are examined as shown in Fig. 3(a). It was found that the nanoarray has a diameter of $50 \mathrm{~nm}$ and a length of $300 \mathrm{~nm}$. Although the length of $\mathrm{ZnO}$ nanoarray is shorter than the result of others [28, 29], which may be not broken off at the interface of the $\mathrm{ZnO}$ nanoarray and $\mathrm{ZnO}$ seed layer when the samples prepared. In addition, the corresponding selected-area electron diffraction pattern as indicated in Fig. 3(b) revealed the presence of the (002) and (100) planes of wurtzite $\mathrm{ZnO}$. Furthermore, the high-resolution TEM images as indicated in Fig. 3(b) revealed that it had highly crystallinity and was grown along the c-axis [001] direction with the $0.26 \mathrm{~nm}\{001\}$ lattice fringe parallel to the basal plane [30].

Fig. 4 shows the room temperature UV-vis measurements for $\mathrm{ZnO}$ doped with different Co concentrations. For all samples, graph is plotted between (ahv) ${ }^{2}$ and band gap energy as shown in Fig. 5. The characteristic absorption peaks at 350-400 nm with absorbance of 1.7 are observed in Fig. 4, which can be associated to intrinsic absorption indicating that $\mathrm{ZnO}$ nanoarrays have excellent ability of light absorption. Actually, the enhanced ultraviolet absorption are basically dependent on the quantum size effect to change the electron level of $\mathrm{ZnO}$. The absorption intensity fluctuates are 
observed with the increase of Co doping concentrations in the visible region, as shown in Fig. 4. The diffusion reflection occurs when sunlight irradiates into the samples with slant nanoarrays, which is not beneficial to absorb sunlight of perovskite layer. The weak absorption of Co-doped $\mathrm{ZnO}$ nanoarrays (4 mol\% and $5 \mathrm{~mol} \%$ ) is caused by numerous Co-ion incorporation in the $\mathrm{ZnO}$ lattice to affect the energy level structure.

Fig. 5 shows the graph plotted between $(\text { ahv })^{2}$ and band gap energy. The optical band gap energy (Eg) curves can be calculated using the following formula [31]:

$$
\mathrm{ahv}=\mathrm{A}(\mathrm{hv}-\mathrm{Eg})^{\mathrm{n} / 2}
$$

Where $\mathrm{a}$ is the absorption coefficient, $\mathrm{h}$ is the Planck constant, $\mathrm{v}$ is the optical frequency, A is the constant, Eg is the band gap. The value of $\mathrm{n}$ for direct band gap semiconductor is 1 (or else is 4). The band gap energy value is acquired by linearly extrapolating the (ahv $)^{2}$ function to zero. The decrease in band gap energy value from $3.22 \mathrm{eV}$ for $\mathrm{ZnO}$ to $3.16 \mathrm{eV}$ for $\mathrm{ZnO}$ doped with $3 \mathrm{~mol} \% \mathrm{Co}$ is attributed to $\mathrm{Co}-\mathrm{ion}$ incorporation in $\mathrm{ZnO}$ lattice respectively. The band gap energy value increases with $5 \mathrm{~mol} \% \mathrm{Co}$ doped $\mathrm{ZnO}$. Due to the Burstein moss effect, resulting in the widening of the band gap. The similar results of decrease in band gap energy in Co-doped $\mathrm{ZnO}$ nanoparticles has been reported by D. Guruvammal et al. [32]. An appropriate amount of Co doping (e.g., 3 mol\%) causes a slightly downward shift of band gap energy, this is helpful for collecting the photo-generated electrons in the pervoskite film with a low energy loss, owning to the reduced difference between band gap energy of $\mathrm{Co}^{2+}$-doped $\mathrm{ZnO}$ and pervoskite materials. On the other hand, cobalt oxide have small band gap energy of $2.8 \mathrm{eV}$ so it is quite reasonable to expect the decrease in energy band gap with the increasing Co doping concentrations.

\section{Growth mechanism of the nanoarray structure}

The schematic diagram of $\mathrm{Co}^{2+}$-doped $\mathrm{ZnO}$ nanoarray growing mechanism and the structure of samples is shown in Fig. 6. The lowest layer is ITO substrate, the second is $\mathrm{Co}^{2+}$-doped $\mathrm{ZnO}$ seed layer spin-coated on ITO and the third is $\mathrm{ZnO}$ nanoarray layer grown on seed layer. A theory that the nucleation tends to form the 
structure with low free energy on the smooth surface, which is easy to take shape the initial orientation is proposed by Yuan [33]. It seemed to be heterogeneous nucleation on the substrate surface and the driving force is the decrease of free energy during transition from unstable amorphous state to crystalline state. Actually, the activation energy of heterogeneous nucleation is much lower than homogeneous nucleation accelerating high nucleation rate on substrate compared to the process in solution. In other words, the seed layer adsorbs $\mathrm{Zn}^{2+}$ ions to form a spherical crystal nucleus, and then the growth unit continues to grow on the crystal nucleus [34]. In general, the preferential growth of $\mathrm{ZnO}$ nanoarray is along the [0001] direction (c axis terminated by $\mathrm{Zn}$ ) because the (002) plane has the lowest surface energy. Normally nanoarrays morphology is obtained because the growth velocity along $<1010>$ is slower than that along the [0001] direction. When $\mathrm{OH}^{-}$is adsorbed on the (0001) surface, more $\mathrm{Zn}^{2+}$ ions attach to the end which gives rise to the formation of nanoarrays. Schematic diagrams depicting the underlying mechanisms of growth for $\mathrm{ZnO}$ nanoarrays are shown in Fig. 6(b). To understand the growth mechanism of the $\mathrm{ZnO}$ nanostructure comprehensively, we reference the restults studied by zhu et al. [35] and Sini et al. [22]. The possible chemical reactions under the hydrothermal conditions are presented as follows:

$$
\begin{array}{rl}
\mathrm{Zn}\left(\mathrm{NO}_{3}\right)_{2} \cdot 6 \mathrm{H}_{2} \mathrm{O} \longrightarrow & \longrightarrow \mathrm{Zn}^{2+}+2 \mathrm{NO}_{3}^{-}+6 \mathrm{H}_{2} \mathrm{O} \\
\mathrm{Co}\left(\mathrm{NO}_{3}\right)_{2} \cdot 6 \mathrm{H}_{2} \mathrm{O} & \longrightarrow \mathrm{Co}^{2+}+2 \mathrm{NO}_{3}{ }^{-}+6 \mathrm{H}_{2} \mathrm{O} \\
\mathrm{C}_{6} \mathrm{H}_{12} \mathrm{~N}_{4}+6 \mathrm{H}_{2} \mathrm{O} \longrightarrow & \longrightarrow 6 \mathrm{HCOH}^{+} 4 \mathrm{NH}_{3} \\
\mathrm{NH}_{3}+\mathrm{H}_{2} \mathrm{O} & \longrightarrow \mathrm{NH}^{+}+\mathrm{OH}^{-} \\
\mathrm{Zn}^{2+}+2 \mathrm{OH}^{-} & \mathrm{Zn}(\mathrm{OH})_{2} \\
\mathrm{Zn}(\mathrm{OH})_{2} & \mathrm{ZnO}+\mathrm{H}_{2} \mathrm{O}
\end{array}
$$

For the growth of nanoarrays, the zinc nitrate was added in the growth solution as precursor to provide $\mathrm{Zn}^{2+}$ (formula 2). HMTA decomposes slowly to formaldehyde and ammonia upon heating (formula 4). Ammonia reacts with water to give $\mathrm{OH}^{-}$as the temperature increases (formula 5), which meets $\mathrm{Zn}^{2+}$ to form a $\mathrm{Zn}(\mathrm{OH})_{2}$ precipitate (formula 6). Upon further heating, $\mathrm{Zn}(\mathrm{OH})_{2}$ produces $\mathrm{ZnO}$ crystals (formula 7). 


\section{Electrical properties}

The linear voltammetry sweeps of $\mathrm{ZnO}$ nanostructure doped with different mol\% Co under chopped solar illumination (AM 1.5G) are shown in Fig. 7(a). The anodic photo-current is observed in the way that once the open-circuit potential is exceeded and the photo-current increase steadily with the applied positive potential [36]. The $\mathrm{ZnO}$ doped with $2 \mathrm{~mol} \% \mathrm{Co}$ exhibit the highest value of $0.15 \mathrm{~mA} / \mathrm{cm}^{2}$ when the Bias voltage is $1.0 \mathrm{eV}$, which is better than the samples doped with 5 or $1 \mathrm{~mol} \% \mathrm{Co}$ and the results studied by Mei et al. [37], Kim et al. [38]. Due to 2 mol\%Co-doped $\mathrm{ZnO}$ has the vertical and compact $\mathrm{ZnO}$ nanoarrays, the photocurrent values of $\mathrm{ZnO}$ nanoarrays are higher than those of other $\mathrm{Co}$ doped $\mathrm{ZnO}$ nanoarrays. Increases in the value of photo-current resulted in the enhancement in electron density triggered by the cobalt doping, which lowers the barrier to electron transfer. Due to the better morphology and complete absorber infiltration into the nanoarray, the transient photo-current value increases to $0.02 \mathrm{~mA} / \mathrm{cm}^{2}$ by Co doping as shown in Fig. 7(b). It can be clearly observed that the sudden generation of charge carriers quickly recombine after generation. The photo-current decay can be attributed to recombination process when the light turn off. In Fig. 7(c), it can be found that the electric current of $\mathrm{ZnO}$ nanoarry nearly approach to zero without AM $1.5 \mathrm{G}$ simulated sunlight illumination because of the appearance of photogenic electron hole pairs .

The electrochemical impedance spectroscopy (EIS) of Co-doped ZnO nanoarry is employed in the frequency range from $80 \mathrm{kHz}$ to $1 \mathrm{kHz}$ (shown in Fig. 7(d)), all of which consisted of an arc in the high-frequency range and a sloped line in the low frequency region. The diameter of the semicircle corresponds to the interfacial charge-transfer resistance, which represents the resistance of electrochemical reactions on the electrode [39]. Obviously, at the initial stage, the value about $10 \Omega$, which is much lower than others, revealing the faster charge transfer in Co-doped $\mathrm{ZnO}$ thin films (2\%). The fact confirms that the incorporation of Co can preserve the high conductivity of $\mathrm{ZnO}$ nanoarray and greatly enhance rapid electron transport, resulting in significant enhancement in the electrochemical performances. 


\section{Conclusion}

In summary, the $\mathrm{ZnO}$ nanoarray have been synthesized on the $\mathrm{Co}^{2+}$-doped $\mathrm{ZnO}$ seed layers by hydrothermal method. XRD confirms the formation of hexagonal wurtzite phase, thus marking the absence of secondary phase formation. The nanoarray are perpendicular to the ITO substrate surface along (002) plane with 60 $\mathrm{nm}$ in diameter and $300 \mathrm{~nm}$ in length, which provide a direct channel to transfer electron. The UV-vis spectra indicate the decrease to $3.16 \mathrm{eV}$ in band gap energy on increasing the dopant $(\mathrm{Co})$ concentration in $\mathrm{ZnO}$. Further, the photo-current increase steadily with the applied positive potentia once the open-circuit potential is exceeded. The transient photo-current of the samples are improved with Co doping and the value increase to $0.15 \mathrm{~mA} / \mathrm{cm}^{2}$. These investigations provide the evidence that the application of $\mathrm{ZnO}$ is improved as an electron transport layer in perovskite solar cells.

\section{Acknowledgements}

The work was supported by the Natural Science Foundation of Henan Province (No. 162300410088) and the China Postdoctoral Science Foundation (No. 2018M632771).

\section{References}

[1] Z. F. Cao, J Zhang, Funct. Mater. 305, 39 (2008)

[2] L. F. Han , N. Cui, Journal of Xi'an Jiao Tong University 90, 47 (2013)

[3] Q. Y. Dong, B. L. Zhang. Inorganic Salt Industry 52, 45 (2013)

[4] J. G. Lv, Z. Z.Ye. Recent advances of $\mathrm{ZnO}$ thin films[J]. Funct. Mater. 581, 33 (2002)

[5] Z. L. Wang, J. Song, Science 242, 312 (2006)

[6] M.Yano, K. Koike, K. I. Ogata et a1, Phys. Status Solidi. 1570, 9 (2012)

[7] B. Richa, P. S. Jitendra, K. H. chae et a1, Vacuum 257, 158(2018)

[8] D. Li, Y. H. Liang, A. B. Djurisic et a1, Appl. Phys. Lett. 1601, 85 (2004)

[9] X. Zhang, J. Qin, Y. Xue et a1, J. Phys. Chem. C 15300, 118 (2014)

[10] W. S. Li, T. Lin, H. T. Yang et al, Jpn. J. Appl. Phys. 6S3, 57 (2018)

[11] A. Balakrishna, M. M. Duvenhage, H. C. Swart et a, Vacuum 376, 157 (2018) 
[12] K. P. Trilok, R. E. Kroon, H. C. Swart et al, Vacuum 508, 157 (2018)

[13] O. F. Kolomys, V. V. Strelchuk, S. V. Rarata et al, Superlattice. Microst. 7, 118 (2018)

[14] M. Louhichi, Z. B. Hamed, S. Romdhane et al, Opt. Mater. 473, 73 (2017)

[15] Y. Liu, Z. H. Kang, Z. H. Chen et a1, Cryst. Growth Des. 3222, 9 (2009)

[16] Yun S , Guo T , Li Y et al, Mater. Res. Bull. 110935, 130(2020)

[17] X. L. Wen, Z. Chen, Funct. Mater. 892, 40 (2009)

[18] M. A. MKhan, R, Siwach, S. Kumar et al, J. Mater. Sci. Mater. El. (6)2020

[19]D. Kumbhar, S. Kumbhar, A. Dhodamani et al, Inorg. Nano-Met. Chem. 1, 2020

[20] N. Ahmad, L. Yanxun, X. Zhang et al, J. Mater. Chem. C (2020)https://dio.org/10.1039/D0TC03048A

[21] Q. K. Shi, Q. Li, L. H. Li et al, Electronic Components and Materials 25, 37 (2018)

[22] K. Sini, S. Biswarup, M. Satyabrata et a1, Chem. Chem. Phys. 12741, 16 (2014)

[23] M. Khalid, Arshi K., Mater. Lett. 78, 224 (2018)

[24] Q. K. Shi, Q. Li. L. H. Li et al, Electron. Compon. Mater. 25, 37 (2018)

[25] T. Hao, H. Deng, Z. Liu et a1, Appl. Surf. Sci.4906, 257 (2011)

[26] J. T. Chen, J. Wang, R. F. Zhuo et al, Appl. Surf. Sci. 3959, 255 (2009)

[27] G. J. Li, H. M. Wang, G. Yang et al, Ceram. Int. 7172, 44(2018)

[28] C. H. Hsu, D. H. Chen, Nanotechnology 285063, 21 (2010)

[29] Z. H. Wang, C. C. Yang, IEEE Trans. Electron Devices 251, 65 (2018)

[30] W. Y. Wu, J. M. Ting, Cryst. Eng. Comm. 1433, 12 (2010)

[31] R. A. Vanleeuwen, C. J. Hung, D. R. Kammler et a1, J. Phys. Chem. 15247, 99 (1995)

[32] D. Guruvammal, S. Selvaraj, S. M. Sundar et al, J. Magn. Magn. Mater. 335, 452 (2017)

[33] L. Yuan, Huazhong University of Science and Technology, 46, (2008)

[34] G. H. Jiang, J. S. Jiang, J. Mater. Sci. Eng. 753, 21 (2003)

[35] L. Zhu, Y. Q. Li, W. Z et al, Appl. Surf. Sci. 281, 427 (2017)

[36] L.W. Zhang, R. Erwin. J. B. Jeremy, Energy Environ. Sci. 1402, 7 (2014) 
[37] J. Mei, H. Zhou, C. Ye et al, J. Sel. Top. Quant. IEEE Electron. 53, 23 (2017)

[38] Y. K.Kim, S.H. Wang. S. Kim et al, Sensor. Actuat. 1106, 240 (2017)

[39] X. Zheng, Y. H. Sun, X. Yan et al, J. Colloid Interf. Sci. 155, 484 (2016) 


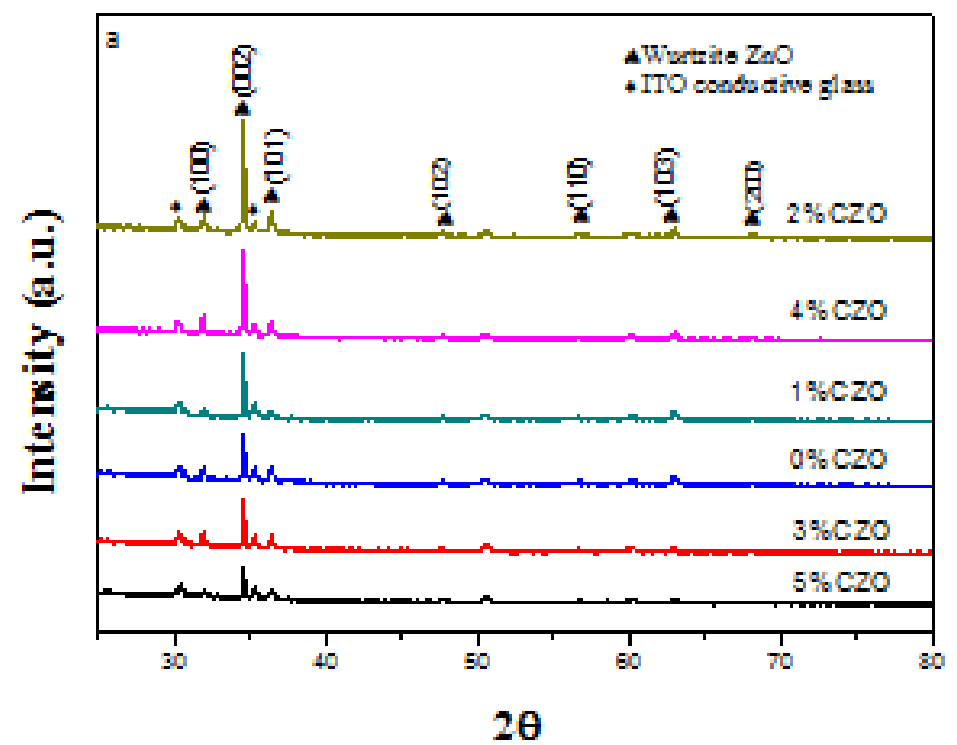

Fig. $1 \mathrm{XRD}$ patterns of the Co-doped $\mathrm{ZnO}$ nanoarrays doped with different Co concentrations 

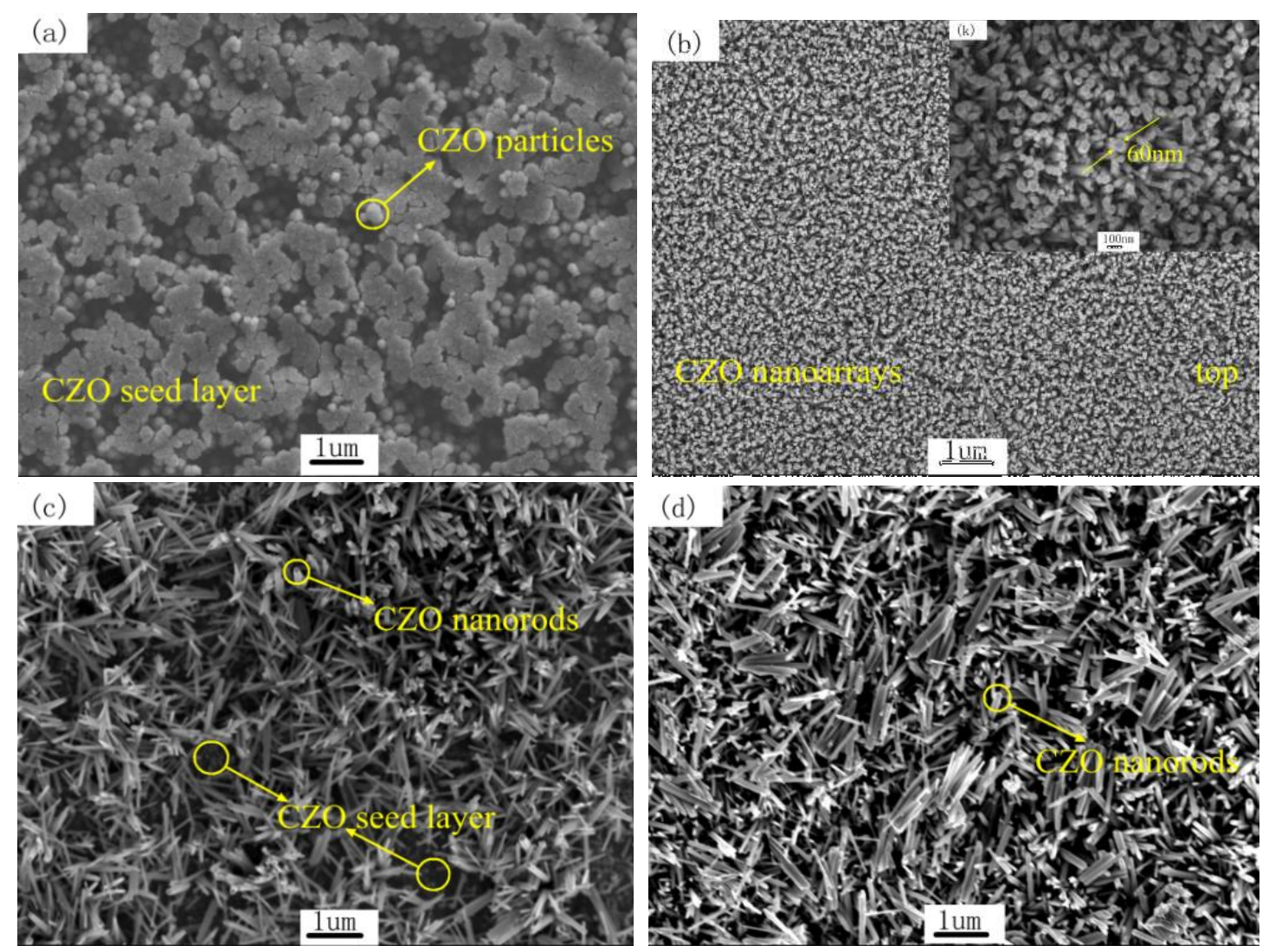

Fig. 2 FESEM images of the samples prepared in (a) 2 mol\% Co-doped $\mathrm{ZnO}$

seeds; (b) $2 \mathrm{~mol} \%$ CZO nanoarrays, $50 \mathrm{mmol} / \mathrm{L}, 7 \mathrm{~h}$ (c) $3 \mathrm{~mol} \%$ CZO nanoarrays, $50 \mathrm{mmol} / \mathrm{L}, 7 \mathrm{~h}$

(d) $4 \mathrm{~mol} \%$ CZO nanoarrays, $50 \mathrm{mmol} / \mathrm{L}, 7 \mathrm{~h}$ 

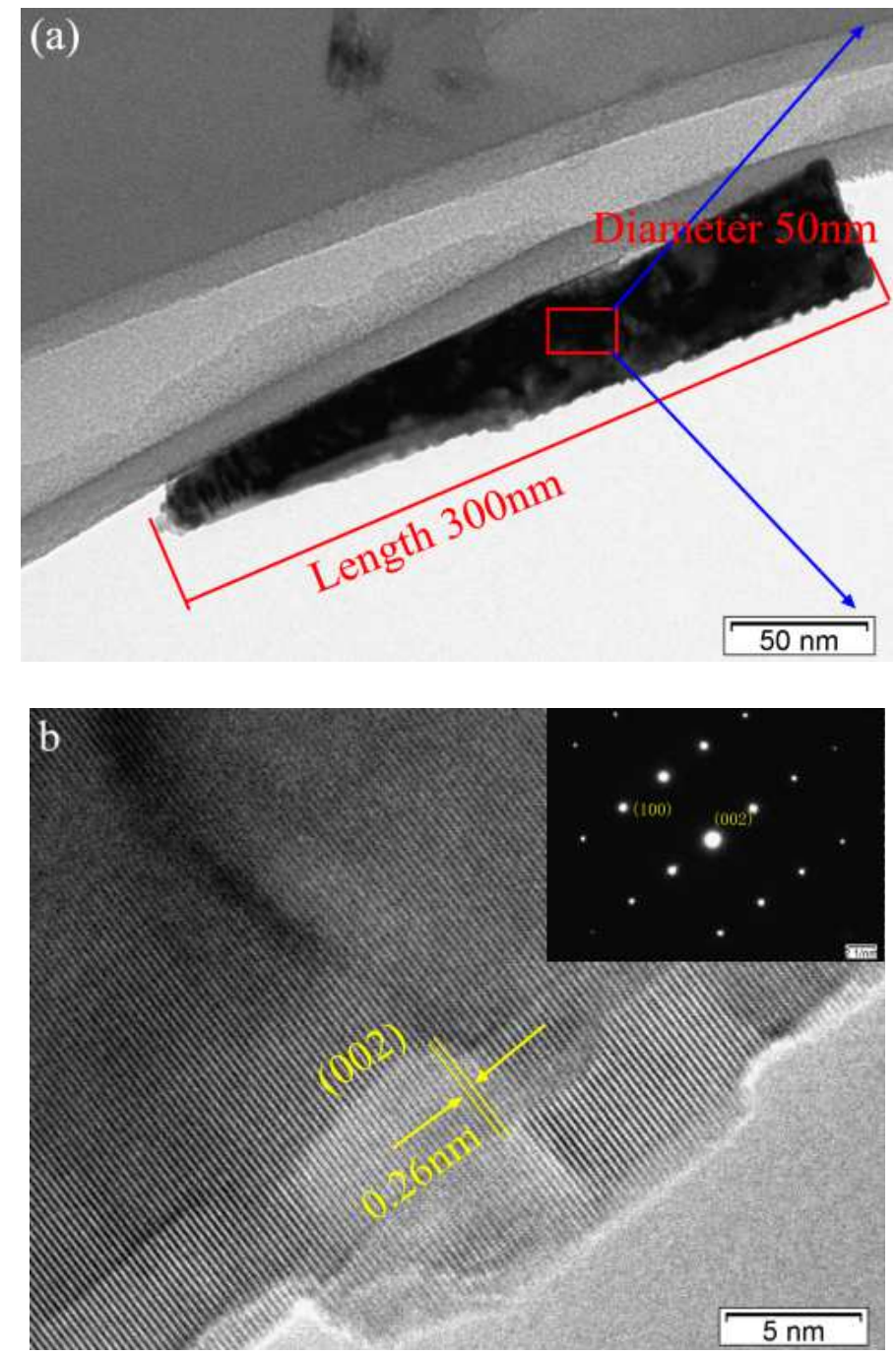

Fig. 3 (a) TEM images an (b) HRTEM images of the CZO nanoarrays doped with $2 \% \mathrm{Co}$ 


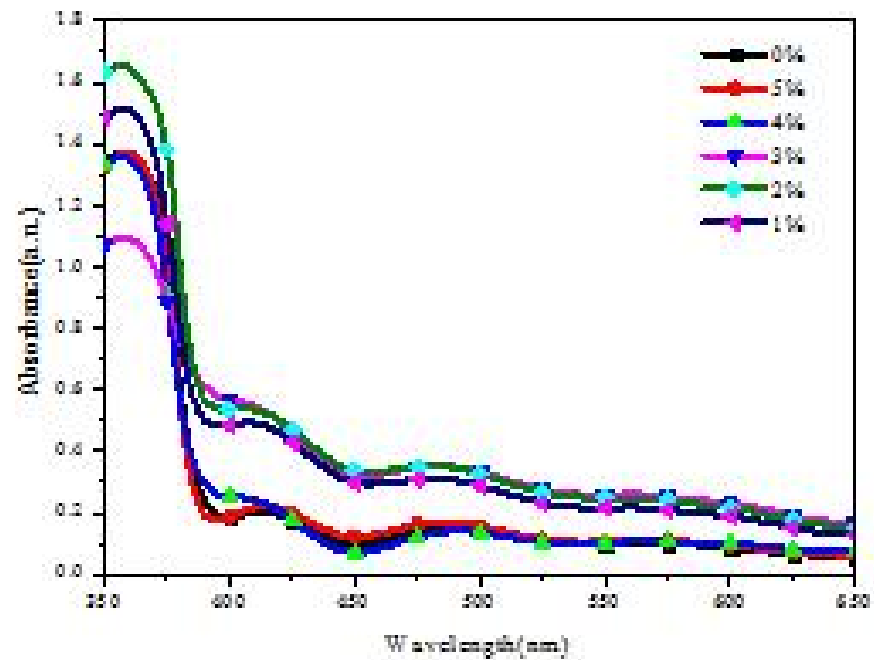

Fig. 4 UV-vis absorption spectra of the $\mathrm{ZnO}$ nsnoarrays doped with different Co concentration 

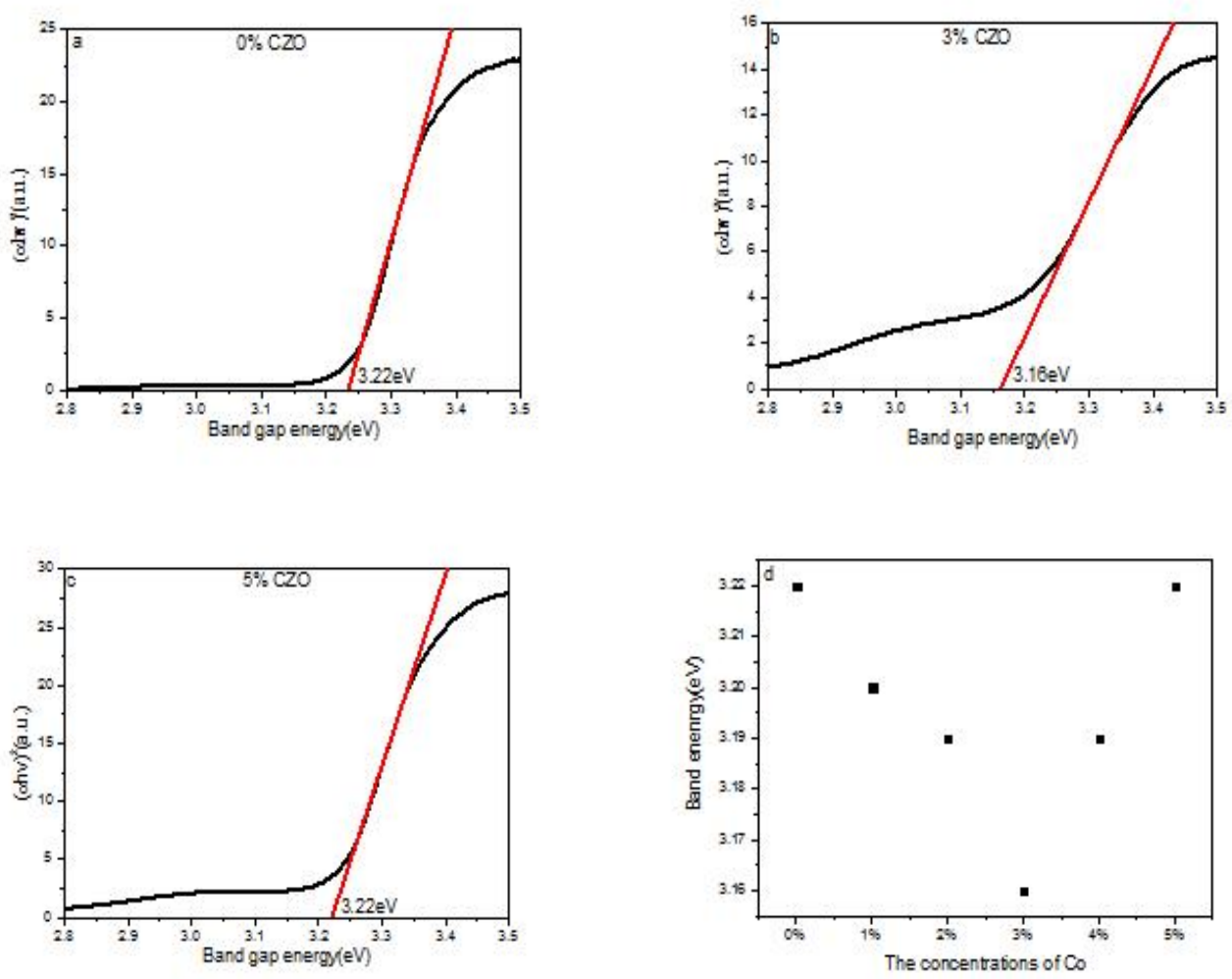

Fig. 5(a-d) Plots of (ahv $)^{2}$ versus photon energy of $\mathrm{ZnO}$ nanoarray doped with different $\mathrm{Co}$ concentrations 


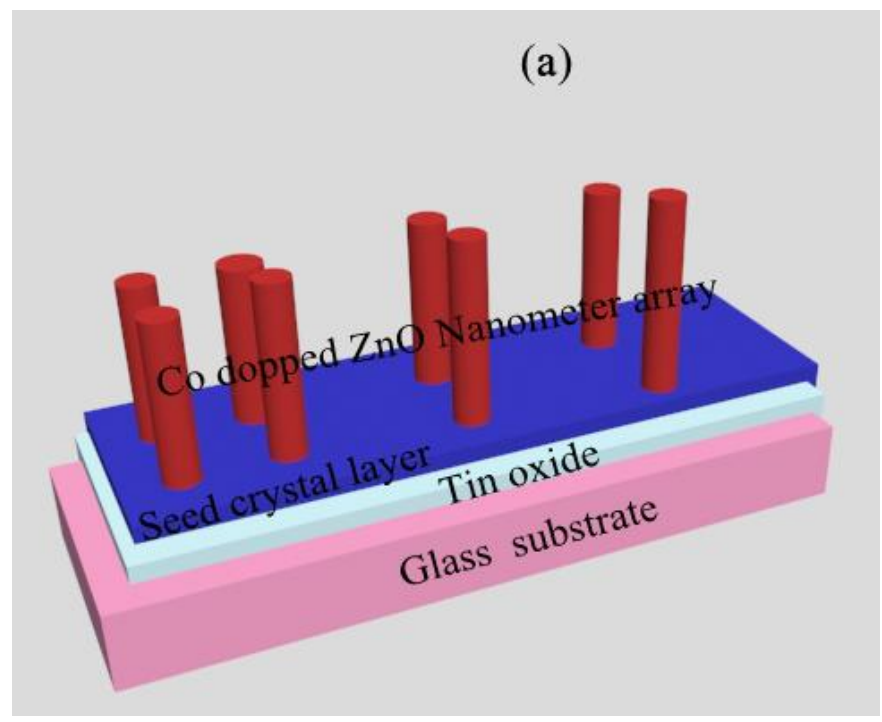

(b)

(002)

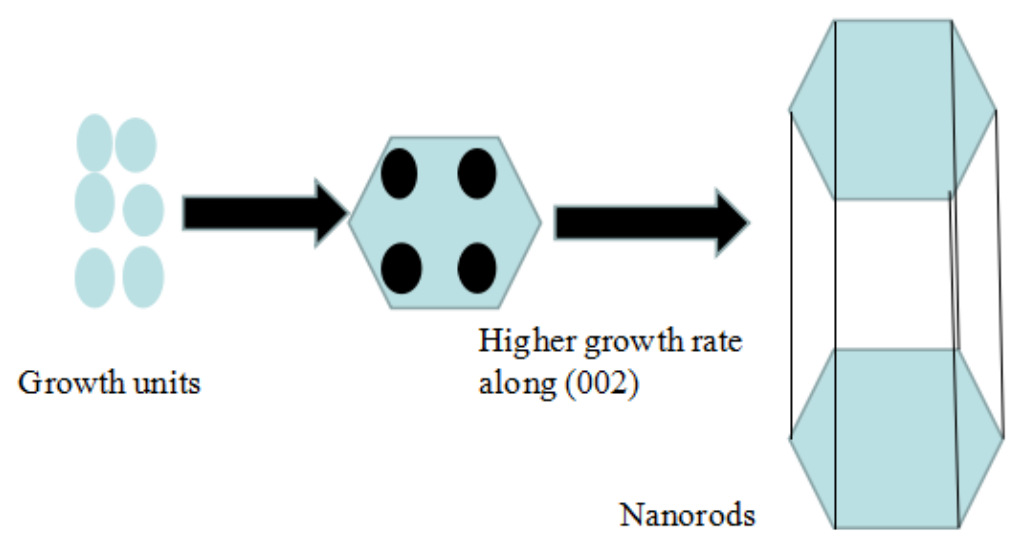

Fig. 6(a) Structural diagram of Co-doped $\mathrm{ZnO}$ nanoarray, (b) formation mechanism of Co-doped $\mathrm{ZnO}$ nanoarray[19] 

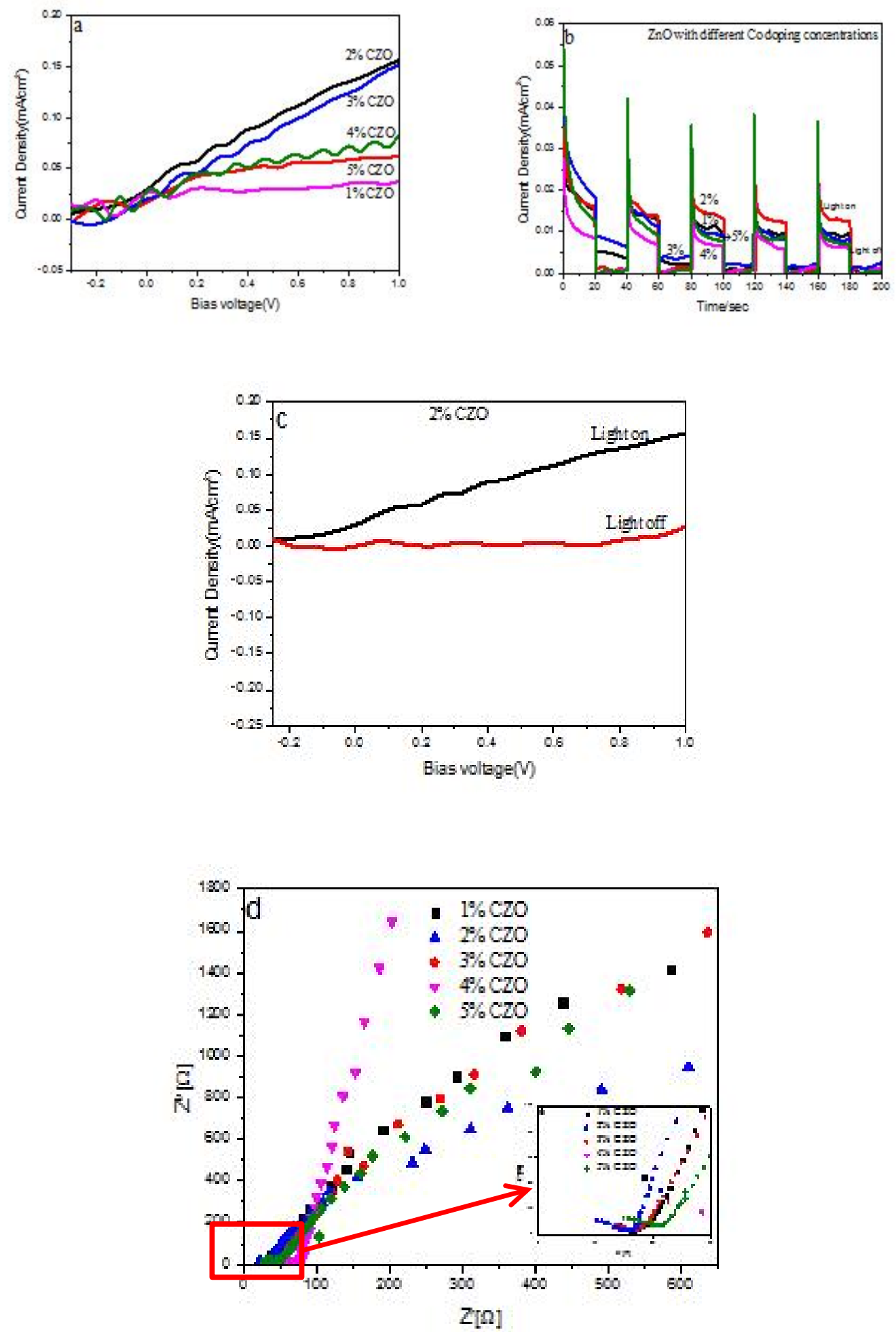

Fig. 7(a) Linear voltammetry sweeps under chopped solar illumination (AM 1.5G), (b) transient photo-current, (c) linear voltammetry sweeps with light on or off, and (d) electrochemical impedance spectroscopy (EIS) of $\mathrm{ZnO}$ nanoarrys doped with different concentrations 
Figures

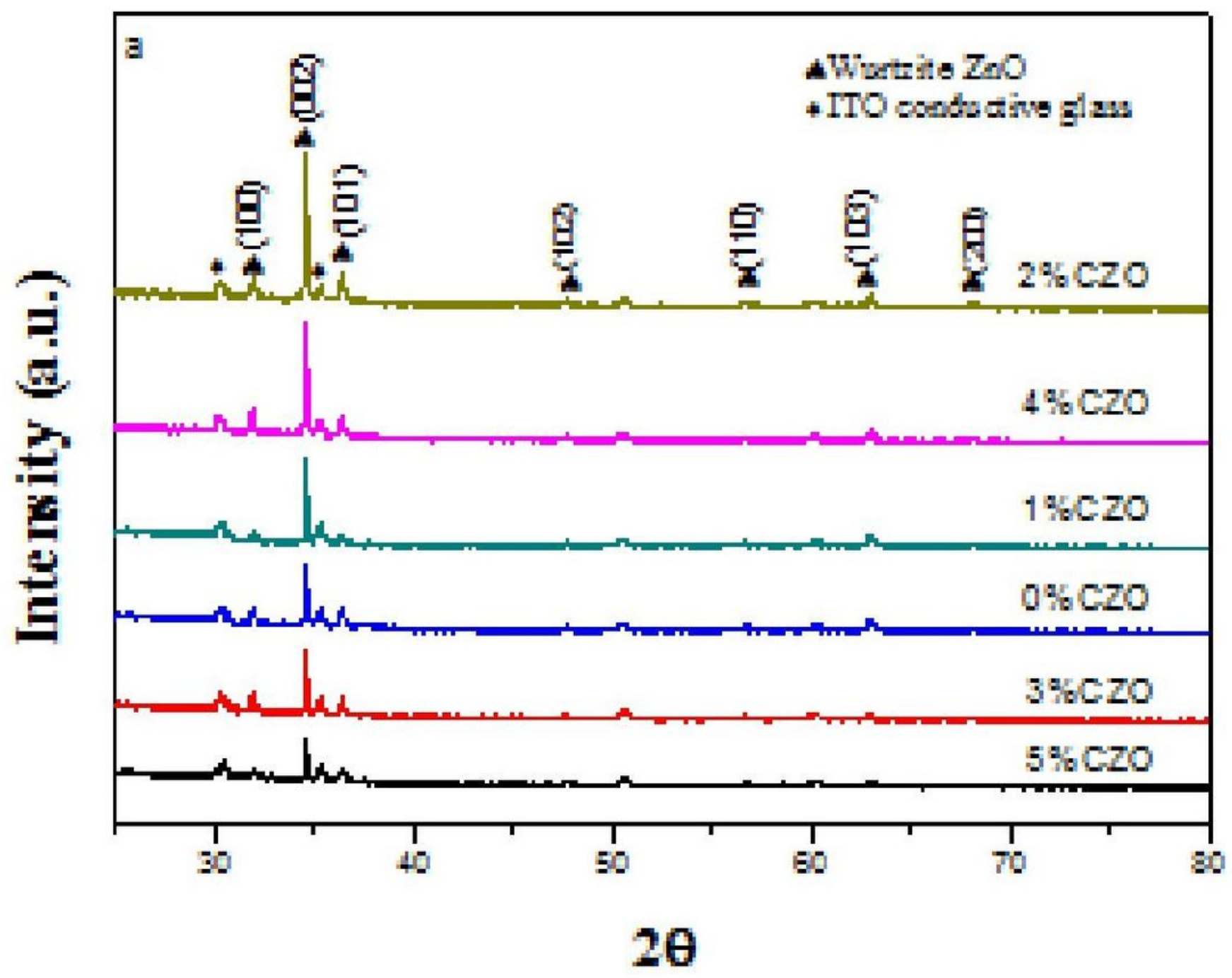

Figure 1

XRD patterns of the Co-doped ZnO nanoarrays doped with different Co concentrations 

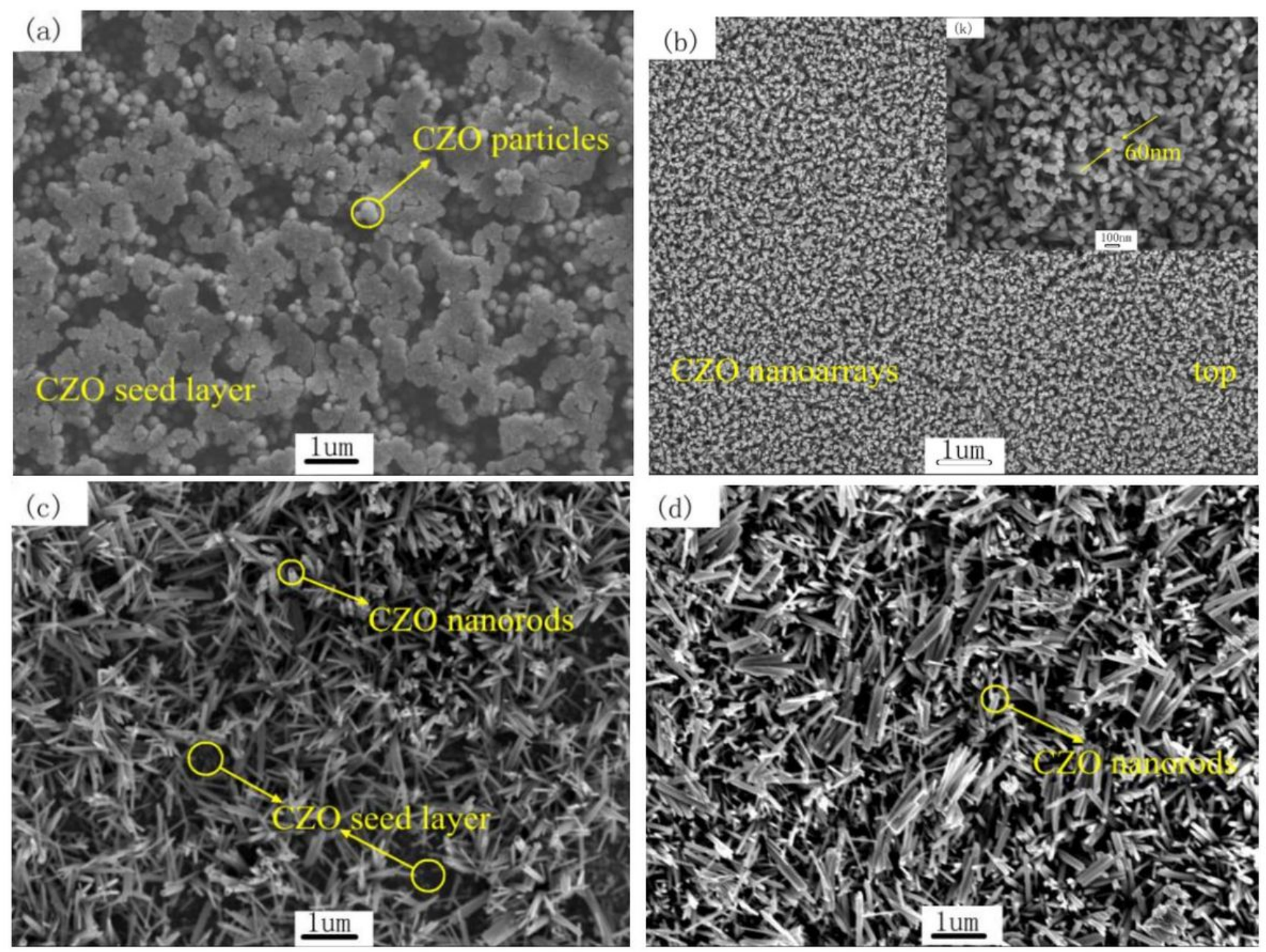

Figure 2

FESEM images of the samples prepared in (a) $2 \mathrm{~mol} \%$ Co-doped ZnO seeds; (b) $2 \mathrm{~mol} \%$ CZO nanoarrays, $50 \mathrm{mmol} / \mathrm{L}, 7 \mathrm{~h}$ (c) $3 \mathrm{~mol} \% \mathrm{CZO}$ nanoarrays, $50 \mathrm{mmol} / \mathrm{L}, 7 \mathrm{~h}$ (d) $4 \mathrm{~mol} \% \mathrm{CZO}$ nanoarrays, $50 \mathrm{mmol} / \mathrm{L}, 7 \mathrm{~h}$ 

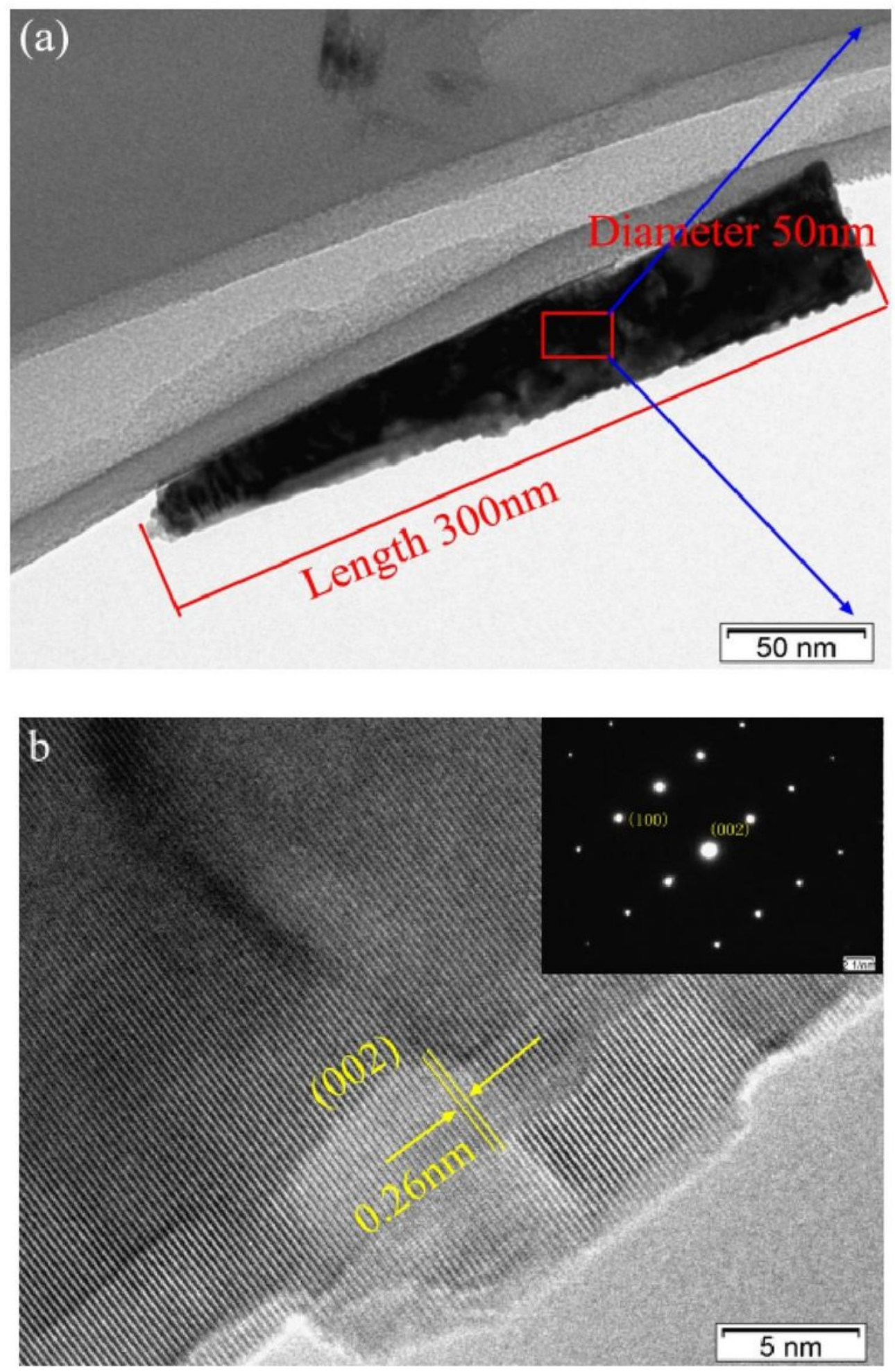

Figure 3

(a) TEM images an (b) HRTEM images of the CZO nanoarrays doped with $2 \%$ Co 


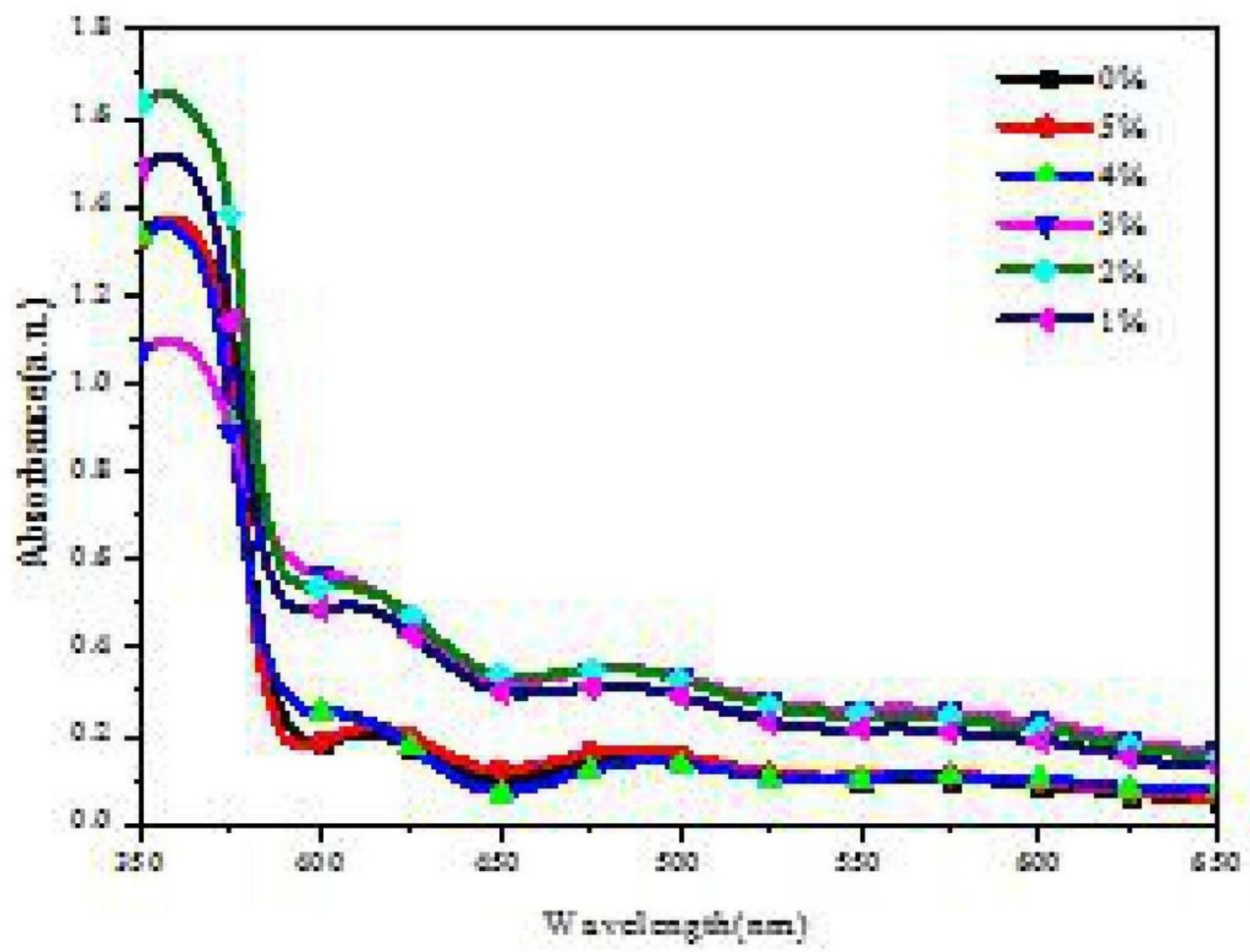

Figure 4

UV-vis absorption spectra of the ZnO nsnoarrays doped with different Co concentration 

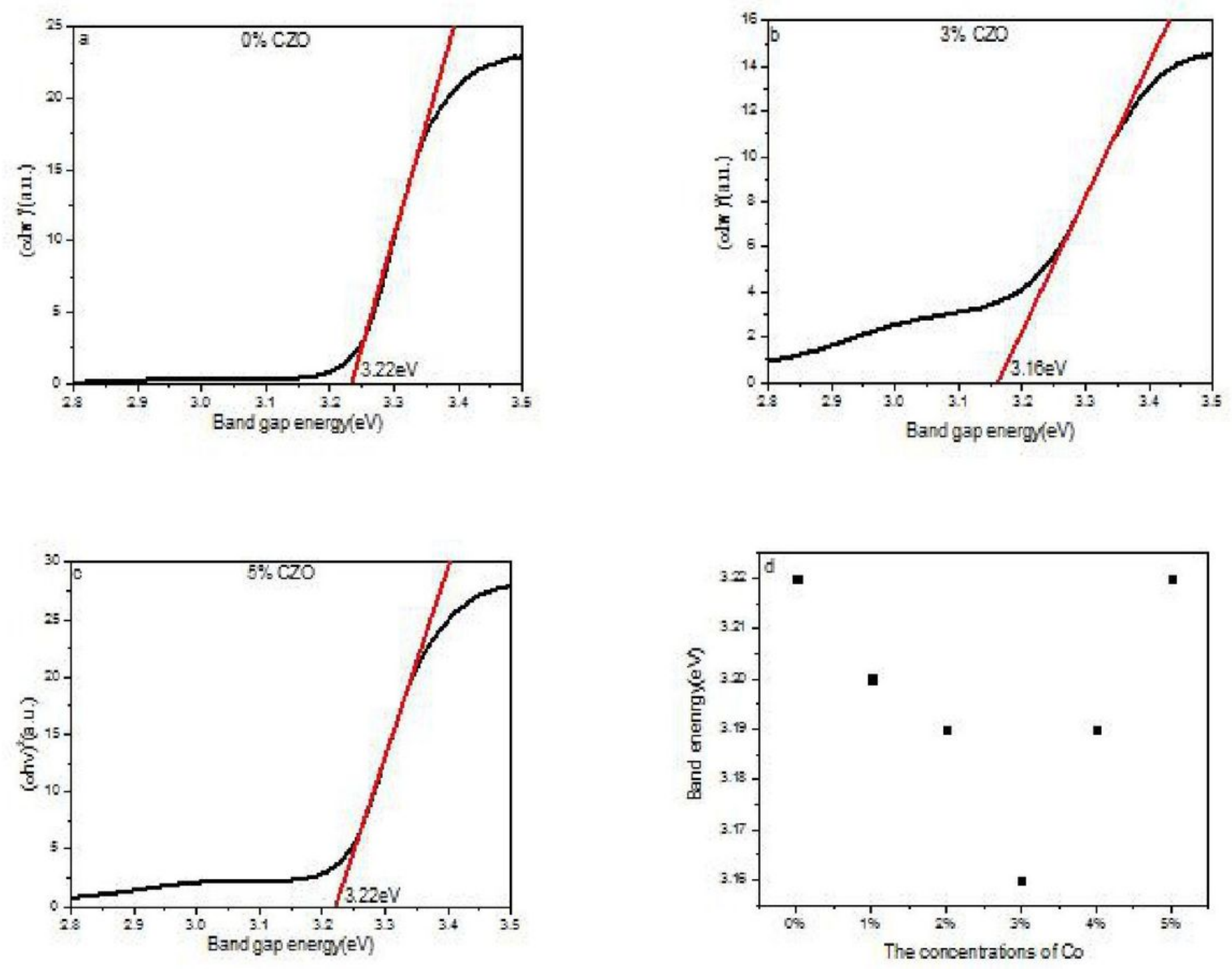

Figure 5

(a-d) Plots of (ahv)2 versus photon energy of ZnO nanoarray doped with different Co concentrations 


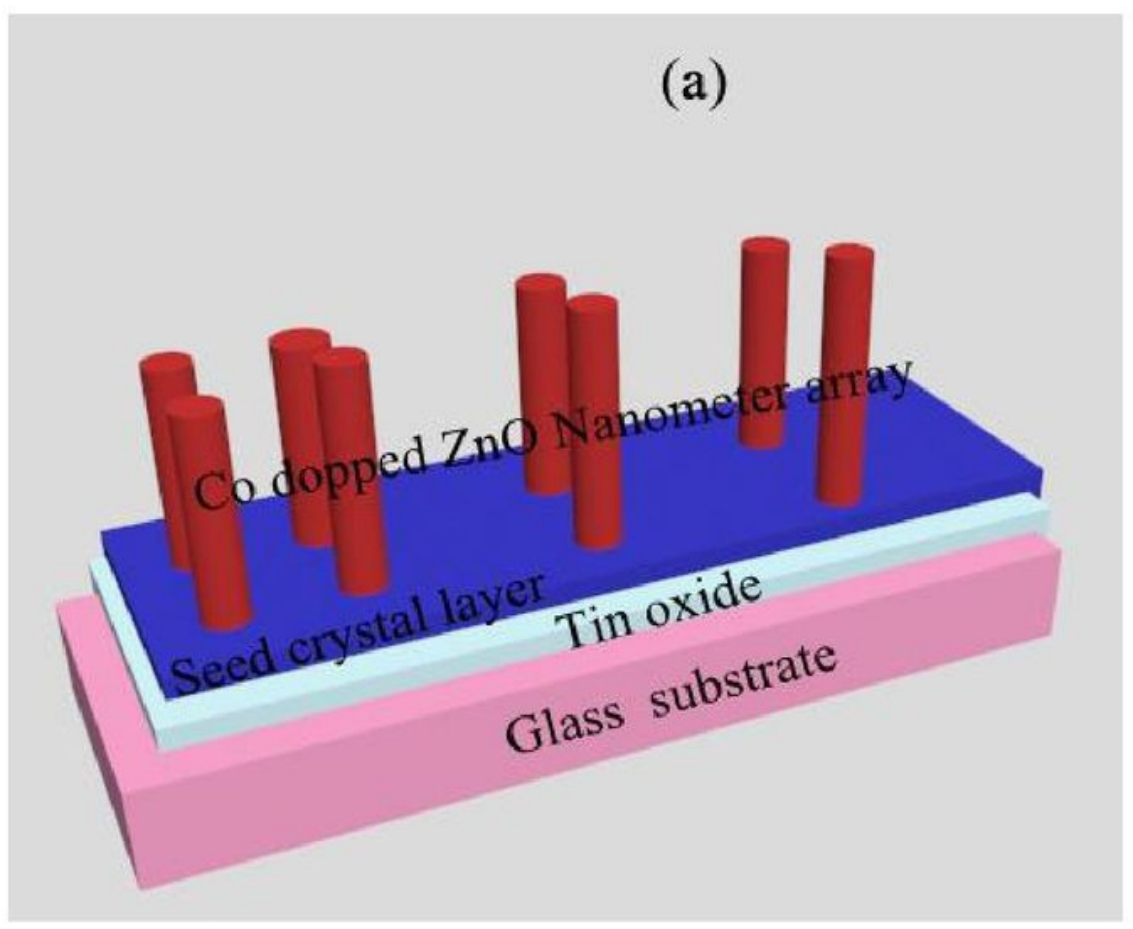

(b)

$(002)$

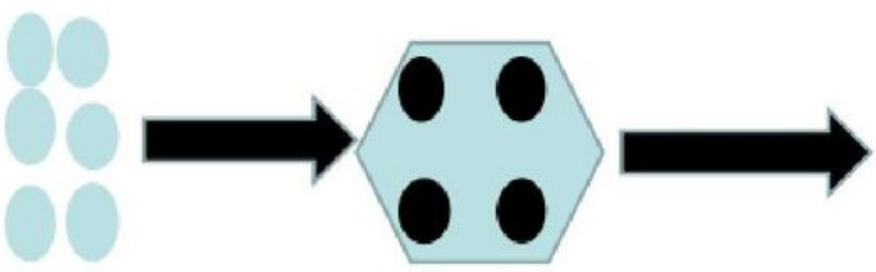

Higher growth rate

Growth units along (002)

Nanorods

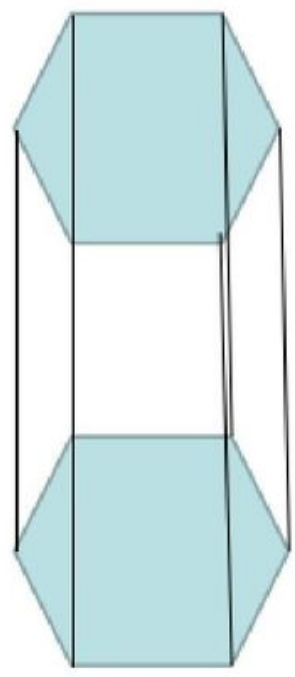

Figure 6

(a) Structural diagram of Co-doped ZnO nanoarray, (b) formation mechanism of Co-doped ZnO nanoarray[19] 

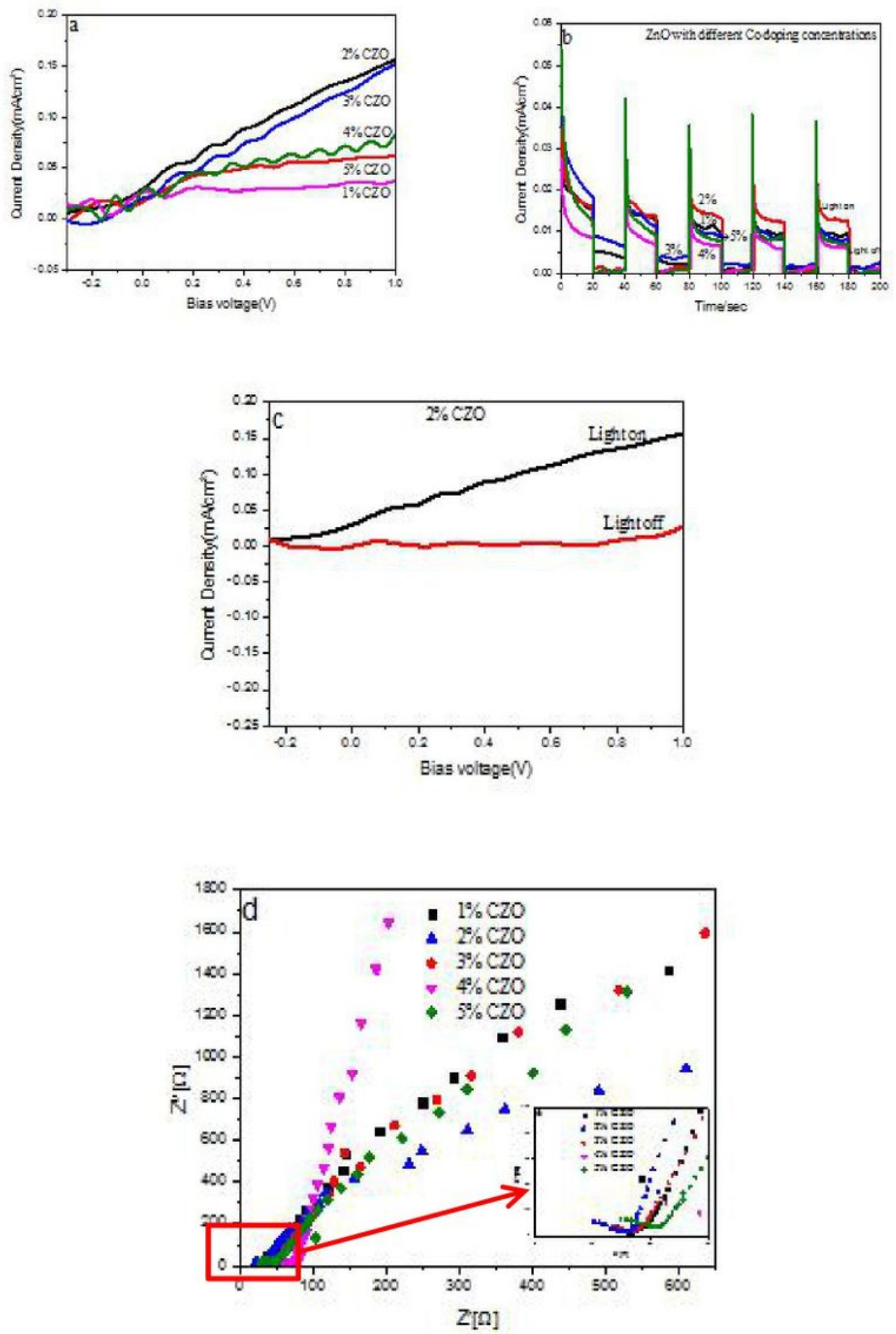

\section{Figure 7}

(a) Linear voltammetry sweeps under chopped solar illumination (AM 1.5G), (b) transient photo-current, (c) linear voltammetry sweeps with light on or off, and (d) electrochemical impedance spectroscopy (EIS) of $\mathrm{ZnO}$ nanoarrys doped with different concentrations 